\title{
Decision Support System for Alarm Rationalization using Risk Assessment Matrix
}

\author{
Oi Mean Foong \\ Universiti Teknologi PETRONAS \\ Bandar Seri Iskandar \\ Tronoh, Perak, Malaysia
}

\author{
Mohamad Izuddin Nordin \\ Universiti Teknologi PETRONAS \\ Bandar Seri Iskandar \\ Tronoh, Perak, Malaysia
}

\begin{abstract}
In this paper, a Decision Support System for Alarm Rationalization using Risk Assessment Matrix (ARRAM) is proposed. When performing alarms review and classifying alarms priority, the ARRAM prototype would be used by process engineers after taking into consideration the safety impact, environmental impact and economic consequences of the hazards. The ARRAM prototype pre-determines the response time available to plant operators before the hazards occur. The objectives of this paper are two-fold: (1) To configure the alarms by using Risk Assessment Matrix and (2) To develop a prototype for classifying the alarms in oil refinery focusing on Crude Distillation Unit. The proposed ARRAM model provides a user-friendly interface for decision maker in making accurate and timely decision when rationalizing random alarms data. Preliminary results show that ARRAM is a useful tool for training new process engineers in familiarizing with alarm management system in oil refinery.
\end{abstract}

\section{Keywords}

Alarm rationalization, Crude Distillation Unit (CDU), Decision Support System, risk assessment matrix.

\section{INTRODUCTION}

Chemical process industry typically has large inventory of hazardous chemicals and often it is highly congested with the existence of composite pipe lines and other related equipments for process operation. Risk assessment matrix in chemical process industry is becoming an increasingly important issue for safeguarding human and ecosystem from damages caused by them. Quite often, alarms are one of the important elements of the safety systems in process plants. They indicate undesired or potentially dangerous situations to plant operators. Alarms are always intended for plant operators to follow-up. Therefore, the most important principle when reviewing alarm systems is identification of the human factors involved. Generally, plant operators are overwhelmed when dealing with huge information overloads. Human may also make mistakes or act too late. A poor functioning alarm system is always noted as a cause to the seriousness of upsets, incident and major accidents. So, human intervention should only be applied to provide a limited reduction of risks.
In the past, there were a large report of major accidents in this world with a number of fatalities, economic downturn, and harm to the environment. This is proved by the multiple series of explosion and fires at:

- BP's Texas City refinery which killed 15 people and injured 170 on March 23, 2005.

- Another explosion occurred on 10 August 2008 in Sunrise propane storage facility in Toronto evacuating thousands of people and killed two [1].

To prevent these accidents from being out of control and to put the risk to a level as low as reasonably practicable, alarm management system need to be improved by classifying the alarm into their respective priority. Poor management of alarm system will put thousands of lives or even million at risk and contribute to losses of million dollars.

Basically, alarms are triggered based on critical parameters in process plant such as flow, humidity level, temperature, and pressure. Each parameter has their respective set points which are determined by operation unit, process engineer, and the plant supervisor. This has been done by the identification and assessment of minor and major risk contributors, which can be achieved using risk assessment matrix.

Clear and understandable alarms are really important to identify the cause of a problem. In other words, when various problems occur such as alarm flood, the Distributed Control System should filter the alarms and provide corrective action for operators to deal with. Eventually, it minimizes the risk involved in oil refinery. In this paper, a DSS Model is proposed to help decision maker such as process engineer in analyzing random alarm data and to make accurate and timely decision.

\section{RESEARCH CONTRIBUTION}

The main contributions in this research are as follows:

- The prototype ARRAM helps novice process engineers to pre-determine or configure the priority of respective alarms during alarm rationalization discussion between operation unit and other plant superiors.

- This ARRAM can be utilized as a useful tool for training new process engineers in familiarizing with alarm management system by considering the economic impact, health and safety impact and also environment impact. 


\section{BACKGROUND STUDY}

Alarm Management System consists of a set of procedures and practices for determining, documenting, designing, operating, monitoring and maintaining and sustaining alarm system. Alarm system is well-known as a contributing factor to the seriousness of upsets, incidents and major accidents [3]. This system is widely used in current process industries that utilize computer-based Distributed Control System (DCS) and covered by the International Standard IEC 61508.

According to Peter Endow, there are three common problems that are linked to alarms namely standing alarms, background alarms and alarms flood [4]. Several attempts had been made to reduce the alarms flood problem but some still persist as major problem and safety-related alarms are a source of real concern.

Alarm management system links with DCS via the Data I/O function which interprets real-time data and alarm messages from DCS. In order to build historical database which contains all the information on triggered alarm, Knowledge Database uses realtime process data and alarm messages. Information captured on triggered alarms is date, time, criticality, and actions done by operators [5]. Quite often, one or two alarms is/are left unattended by panel operators when alarms flood occur. Those alarms will be automatically reset to initial values which are configured earlier.

Decision Support System (DSS) is identified as a business intelligent system which designed to support and provide tools in solving managerial problems that other computerized techniques cannot [2]. This DSS is very useful when facing a problem like developing this ARRAM. It is because in order to get the correct priority of alarms, human judgment and expertise is required and it is too subjective to be automated in a system. C.W. Holsapple and M. P. Sena reiterated that DSS has several advantages such as increasing a decision maker's ability to process knowledge, enhance decision maker's skill to handle large scale or complex problems, fast when making a decision, improve reliability and accuracy of the outcomes and decision process, and encourage decision makers to discover and explore the outcomes or consequences that might be happen in future [6].

Risk assessment is a method which several organizations focus on critical areas of concern and prioritize their use of resources in order to maximize response to the alarms and recovery efforts. Usually, the business and government leaders try to predict the pros and cons that might cause in making strategic decisions by implementing or failing to implement those decisions. The risk assessment matrix can be viewed and analyzed as a rational extension of that process [7].

\section{METHOD}

A site visit was made to the oil refinery plant. Interview was conducted on control engineers in the oil refinery and also the vendor who implemented the Distributed Control System for better alarm management in the refinery.

Fig.1 shows the components or subsystems in DSS model for alarm rationalization using risk assessment matrix. Generally, all data will be retrieved from Internal Data as lock data in DCS. User can communicate with and command the DSS through components such as Consequence Category, Consequence Class and Response Class. Consequence Category acts as a catalyst for the most important subsystem where the knowledge and experience by experts are required to determine the correct criteria for each alarm whilst user interface subsystem is used as an assistant for the decision makers or users to interact with the system.

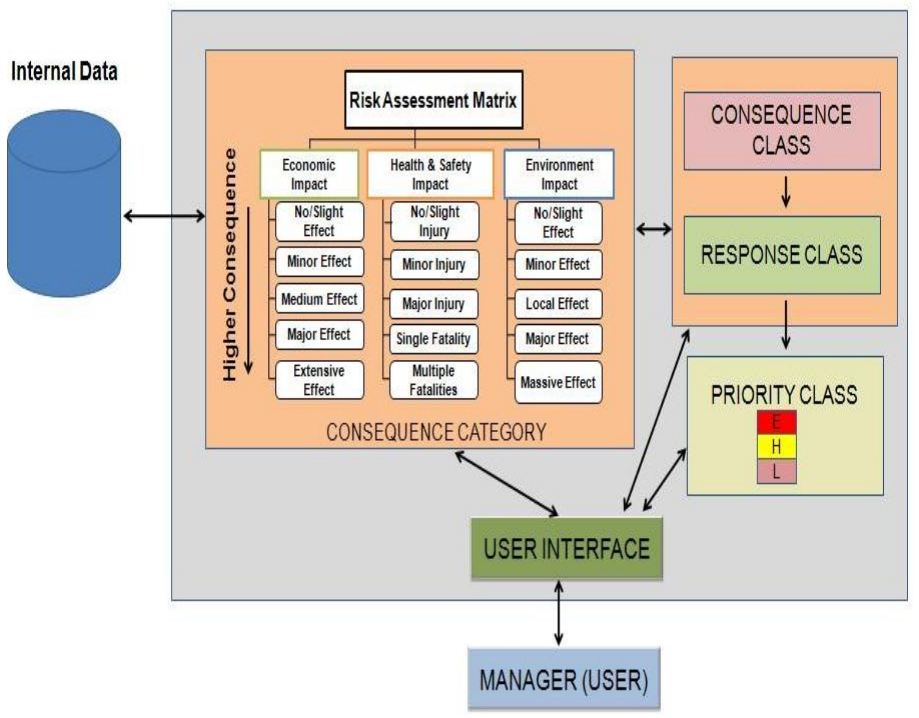

Fig.1 Proposed Decision Support System (DSS) Model for Alarm Rationalization

The proposed alarm rationalization model examines the three impact areas (i.e. economic impact, health \& safety impact and environment impact) and response times taken by panel operators in determining the priority class of the triggered alarms. The alarms are then prioritized as Emergency (E) alarms, High $(\mathrm{H})$ alarms or Low (L) alarms.

Fig. 2 shows the overview of the proposed ARRAM framework. The input will be retrieved from internal data that gather in DCS as lock data. It is because this ARRAM is not run on fly system and the back end value is not involved with actual parameter. All the potential impacts need to be selected first before rationalizing it using Risk Assessment Matrix. Rationalization rules will link and prioritize all selected impacts and response time and perform decision making process.

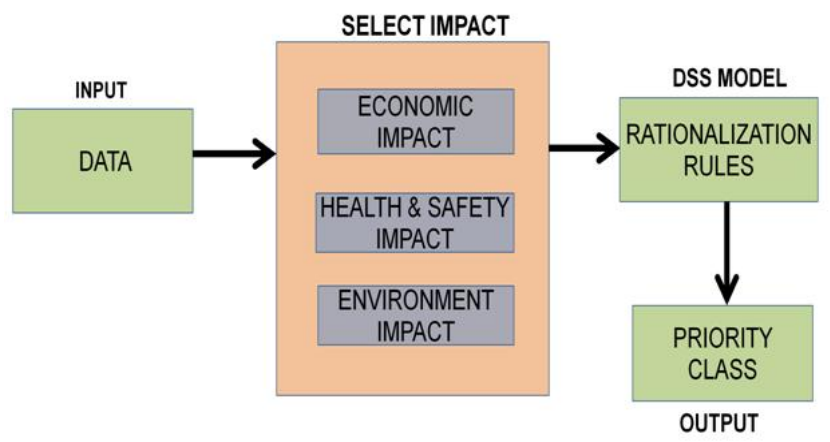

Fig. 2 An Overview of the Proposed ARRAM Framework 
All process flow involved in the prototype is described in Fig.3. The input data will be extracted first from DCS and all the possible consequences need to be determined. Rationalization rules will be fired if the antecedents (conditions) are met for economic, health and safety and environment impacts. It would in turn relate those impacts with the response time to produce the right consequence class as the output.

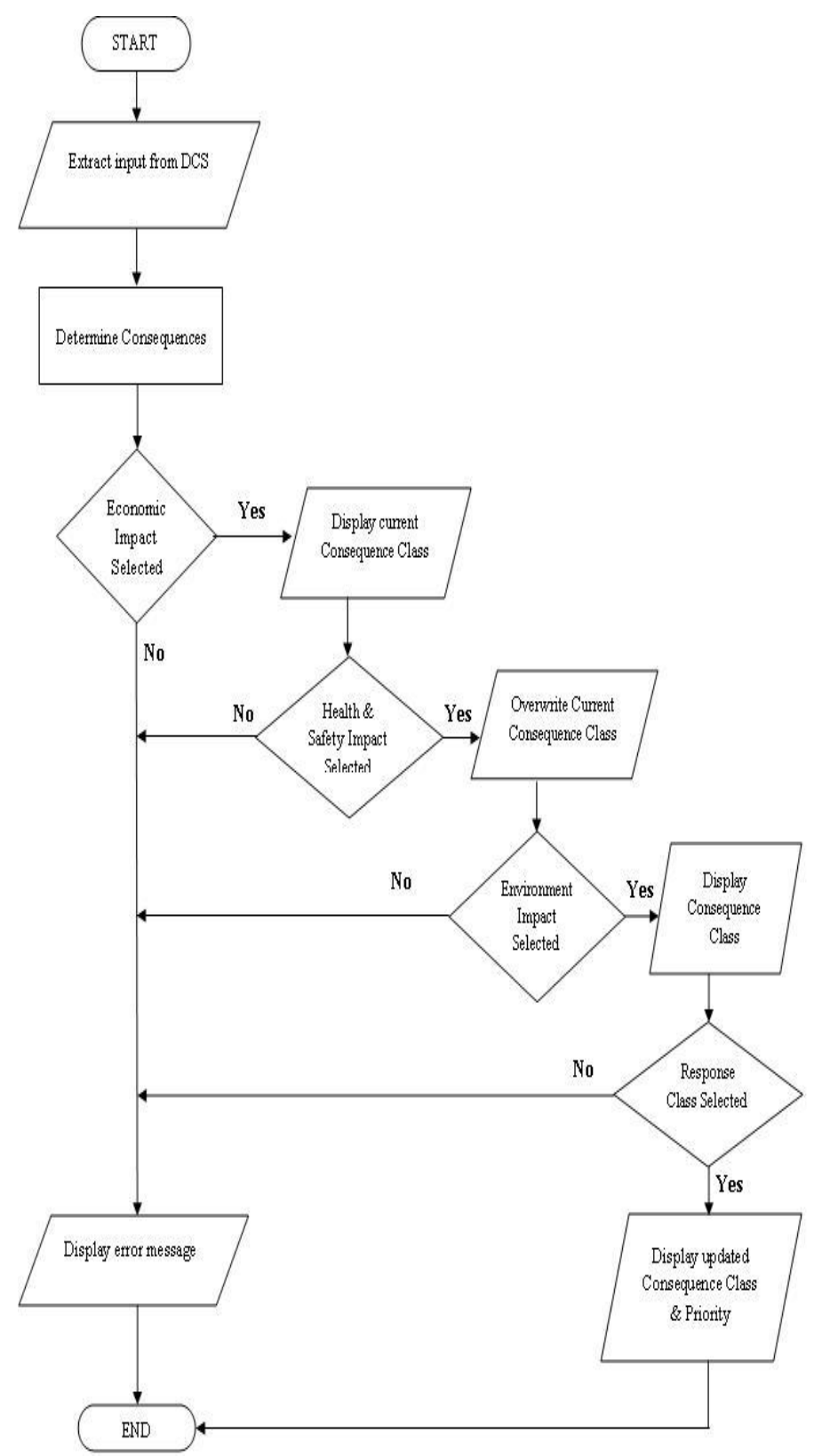

Fig. 3 Flow Chart of Alarm Rationalization Process

\section{DISCUSSION AND ANALYSES}

From the interview conducted, a number of cases or scenario is investigated to formulate the rules from the risk assessment matrix. The Risk assessment matrix consists of consequence category, consequence class, response class and priority class. An excerpt of sample of questionnaires is shown in the Appendix section.

In order to determine the priority (E=Emergency, $\mathrm{H}=$ High or $\mathrm{L}=$ Low) of each alarm in the DCS alarm system, the operation engineers, technologist, control engineer, accountant need to sit together and discuss to determine the exact value of every consequence category. For operation unit, they are responsible to determine the available response class to operator while technologist in charge will decide the consequence class if the alarm is left unattended. Control engineer is accountable for modifying the alarms setting in main control room while the accountant would determine the economical impact to find the exact value of production losses.

Examples:

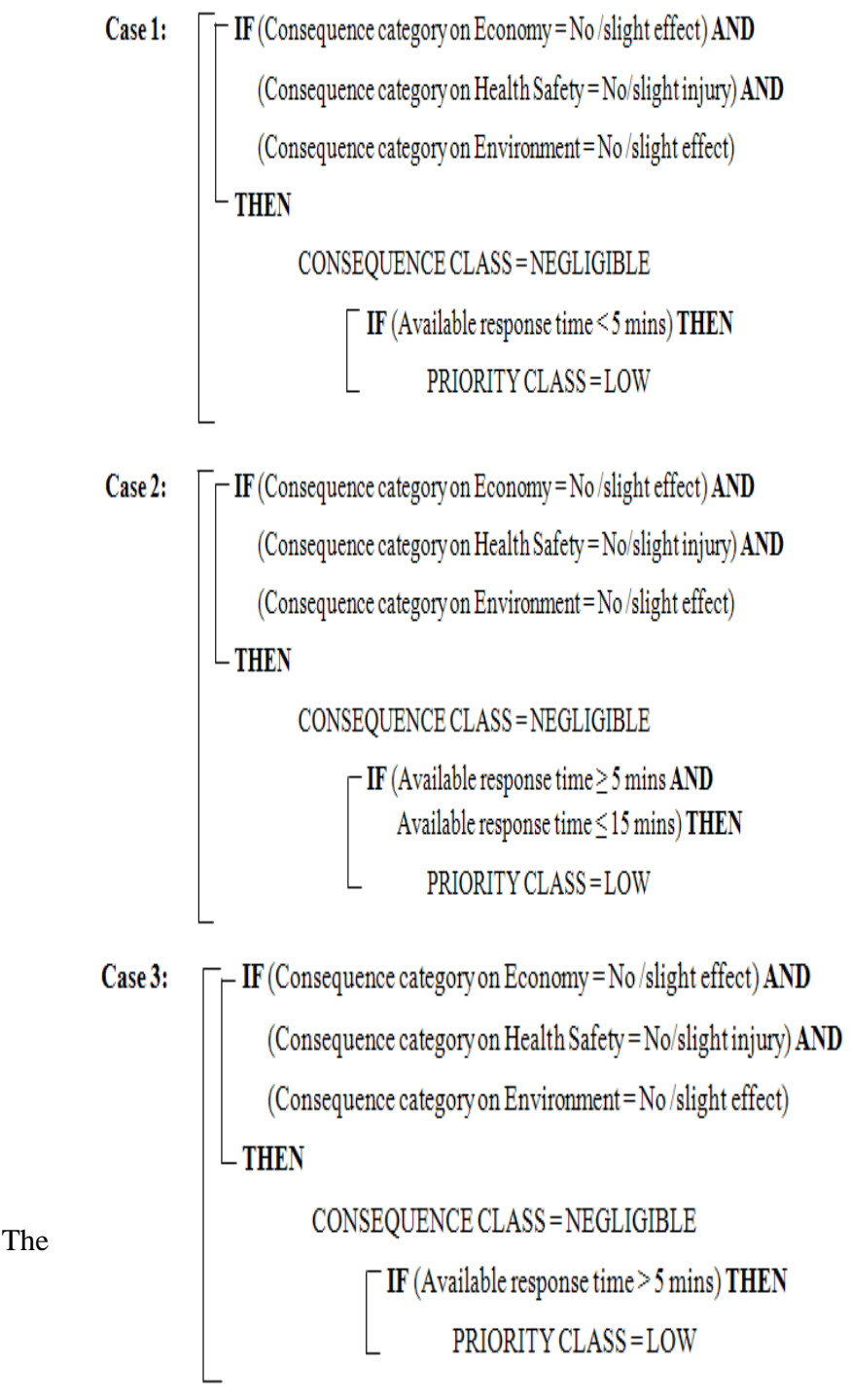

updated priority of alarm can be rationalized after all engineers, including control engineers and operation engineers, technologist, accountant and plant supervisor have discussed and determined 
the exact consequence category can occur if an alarm is left unattended.

Previously, tag number for 21T251 has been set to High consequence class and High priority of alarm as shown in Fig.4. After having discussion among the process engineers, they found out that, the consequence and priority class for this tag number is not suitable. User will have to get new consequence class and new priority class based on these criteria:

- Level is very important in this tank, because tank in CDU need a certain level for it to cater in one time.

- This tag number will give rise to Environmental impact because it will effect surrounding if level of this tank is out of control.

\section{$\therefore$ The consequence category is Major Effect}

- Health and Safety also gives high impact or even extreme in this area. For sour gas scrubbing system, when someone wants to enter the tank that contains sulfur they need to wear special equipment and undergo certified training. They have to climb up the tank and of course this also will affect their health and safety.

$\therefore$ The consequence category for the Health and Safety need to be changed to Multiple Fatalities.

- For Economic impact, it depends on certain situation. If someone got injury or even died, of course the economic loss occurs.

$\therefore$ The consequence category is Major Effect.

- For Response Class, plant operators need to response fast if worst case scenario happened.

$\therefore$ The Response Class is Short ( less than 5 min.).

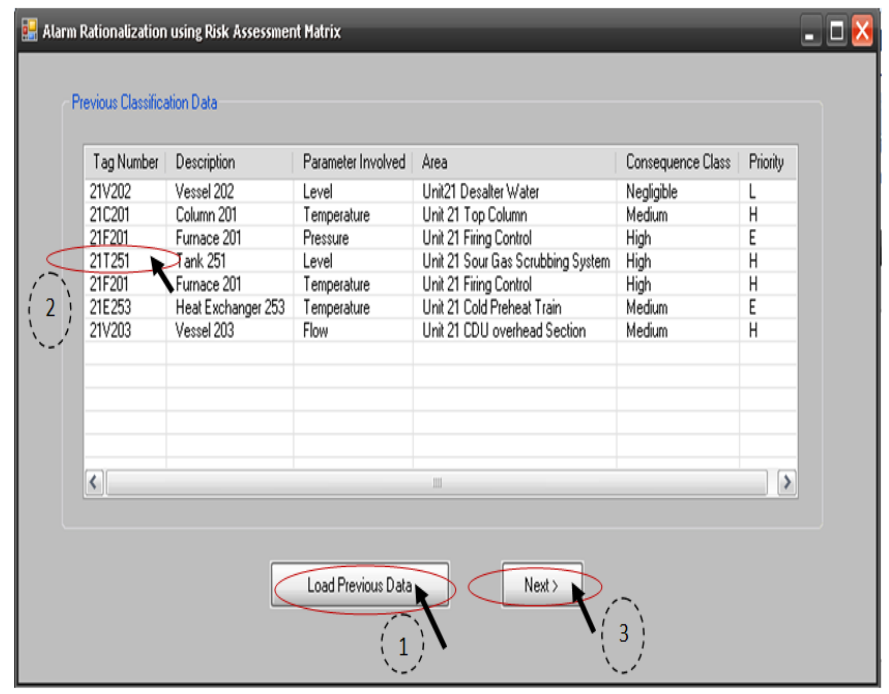

Fig. 4 Previous Classification Data

Fig.5 illustrates what the consequence class is when one of the items (Major Effect 1-10M) in "Economic Impact" Combo Box is selected.

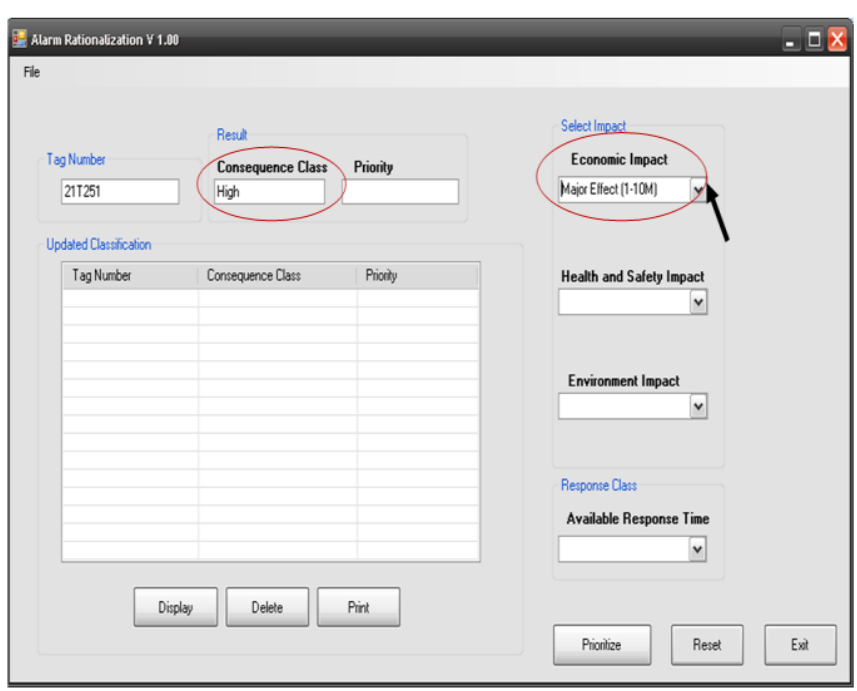

Fig.5 Economic Impact Selected Item

Next, user selected "Major Effect" from "Environment Impact" Combo Box. The Consequence class shown in Fig.6 still remains the same result as "High".

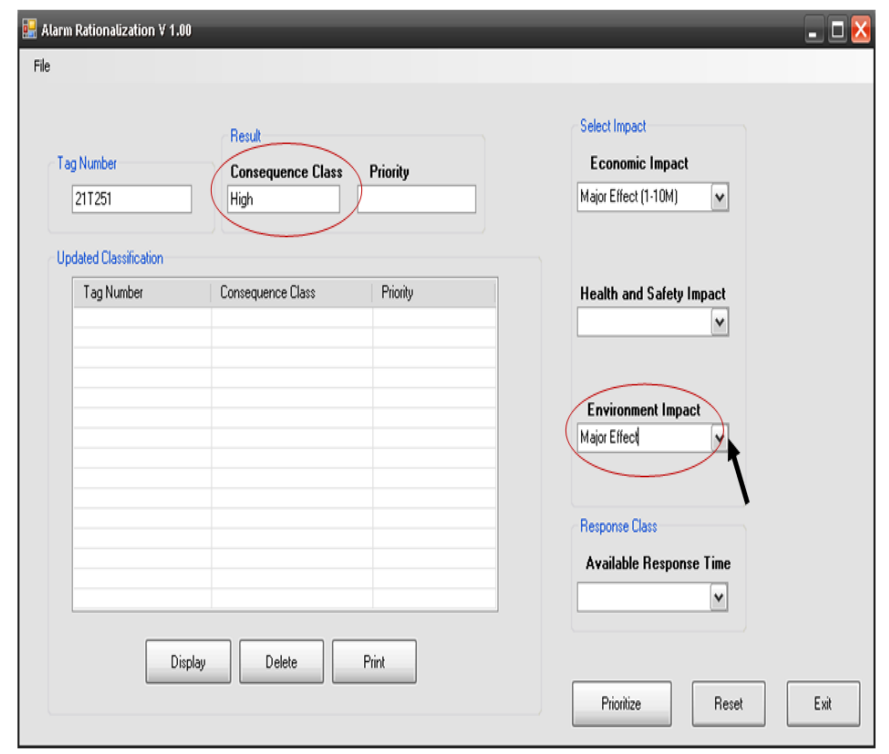

Fig.6 Environment Impact Selected Item

It happened that way because Consequence Class "TextBox" will take the most critical consequence category based on the risk assessment matrix. When Multiple Fatalities have been selected from "Health \& Safety" ComboBox, the output in Consequence Class "TextBox" will be changed to Extreme as shown in Fig. 7. 


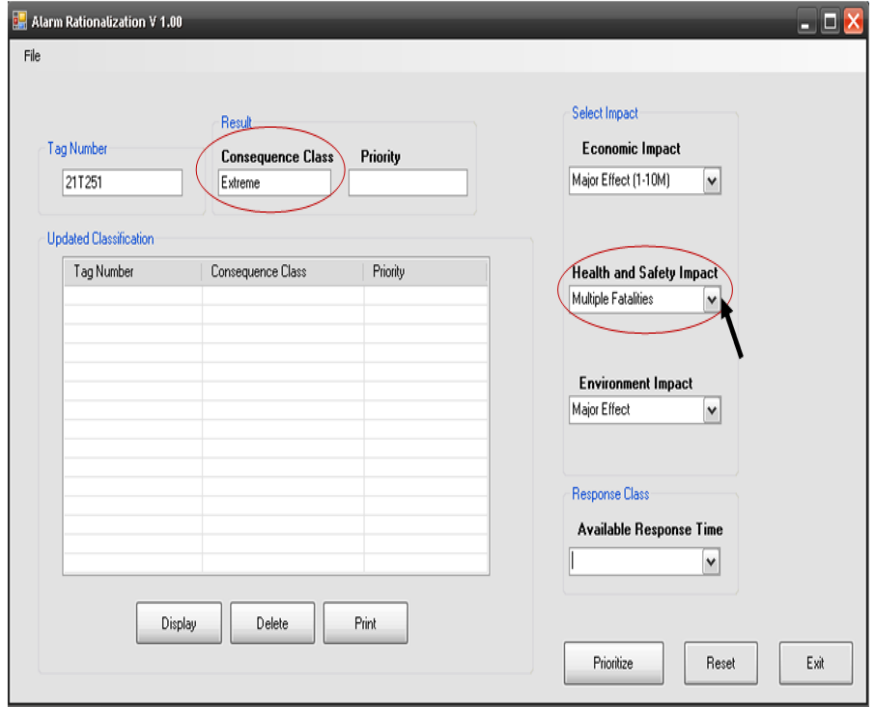

Fig.7 Health and Safety Impact Selected Item

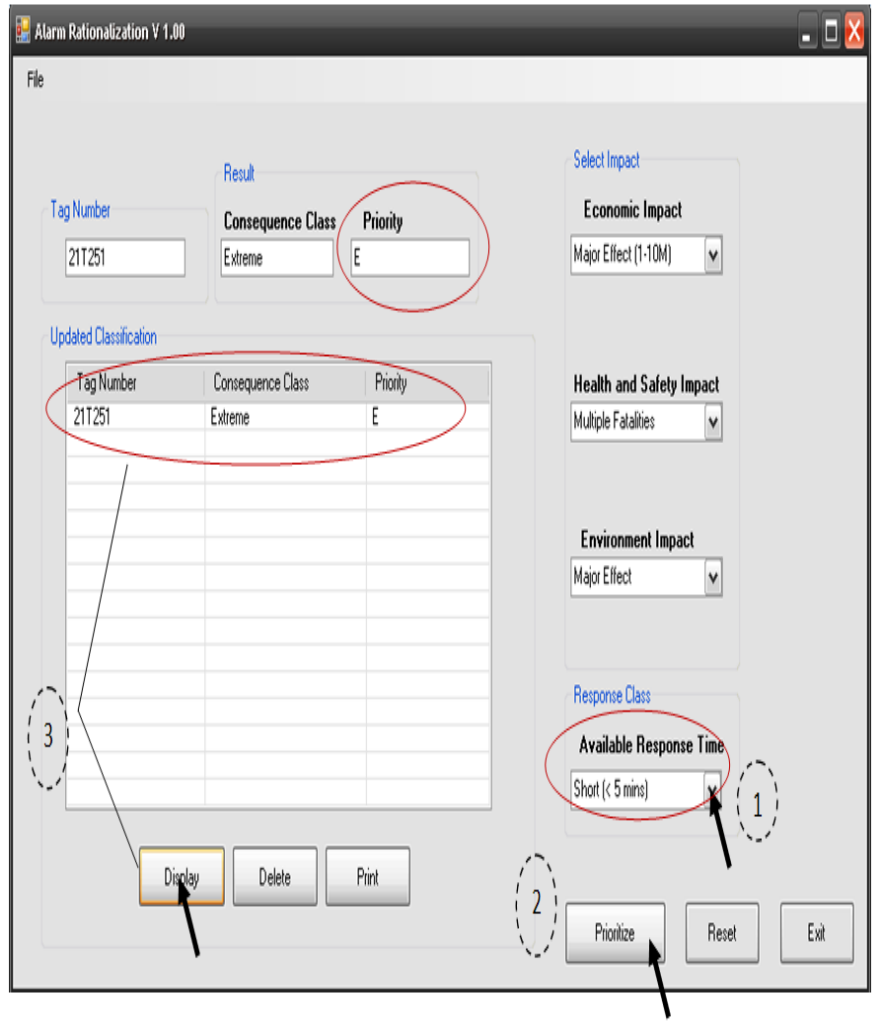

Fig.8 Determine the Priority of Alarms

Fig.8 shows how the priority of selected tag number is displayed. In order to get the "Priority" output, last input from "Response Class" Combo Box need to be determined upon pressing the "Prioritize" button. All information and output can be displayed in "Updated Classification" section by pressing "Display" button. The alarm triggered from location tag number 21T251 in the CDU unit has been classified as Emergency alarm with priority which is labeled as E.

\section{PERFORMANCE EVALUATION}

System evaluation for ARRAM has been conducted and this system has been tested and evaluated by process engineer who has 30 years of industry experience. Based on his vast experiences and knowledge in oil and gas industry, this prototype system has been tested and evaluated by him in order to verify the reliability and accuracy of ARRAM. A set of questionnaire has been created based on Likert Scale and this system is evaluated using 5-point scales format as stated below [8]:

$$
\begin{aligned}
& 1 \text { - Strongly disagree } \\
& 2 \text { - Disagree } \\
& 3 \text { - Neither agree nor disagree } \\
& 4 \text { - Agree } \\
& 5 \text { - Strongly agree }
\end{aligned}
$$

Table 2. System Evaluation Result

\begin{tabular}{|l|c|}
\hline \multicolumn{1}{|c|}{ Questions } & Evaluation based on Likert Scale \\
\cline { 2 - 2 } & Process Engineer \\
\hline Is the system easy to use and user friendly? & 4 \\
\hline Are the result produced by the system understandable? & 3 \\
\hline $\begin{array}{l}\text { Are the outputs you get in this system correct and } \\
\text { relate to Risk Assessment Matrix? }\end{array}$ & 4 \\
\hline $\begin{array}{l}\text { Is the system helpful in assisting engineers and } \\
\text { operation unit in alarm rationalization? }\end{array}$ & \\
\hline \begin{tabular}{l} 
Is the system produce accurate result? \\
\multicolumn{1}{|c|}{ Average }
\end{tabular} \\
\cline { 2 - 2 }
\end{tabular}

\section{CONCLUSION}

Alarms are good indicator for safety status in process plant. Alarms if left unattended will contribute to plant shutdown and give big impact to the environment, health and safety and also economic. By using ARRAM, the alarms can be configured by taking into consideration the economic impact, health and safety impact and also the environment impact. Based on the outcome of system evaluation, the rationalization of alarms in oil refinery using risk assessment matrix produces satisfactory result. The prototype ARRAM is a useful tool for novice process engineer to configure the alarm using risk assessment matrix. For future work, we will explore fuzzy optimization techniques in prioritization of alarms in the control room of refinery plant [5],[9],[10],[11],[12]. 


\section{APPENDIX}

Q1. Based on your experiences in chemical process industry, could you please determine which area have frequent of alarms?

Answer: Actually, it is based on place or certain area. For example in area like column, the Flow and Level frequently produce the alarm.

Q2. I want to get your opinion regarding the Tag Number in this prototype. Does it relate to the real situation which has been practiced in refinery?

Answer: Most of the tag number is an indicator. So, if you want me to categorize it based on consequences, we must take a look first at what type of impact will happen in that area. Then choose the appropriate consequences in order to produce the right priority of the alarm. The Tag number must be relevance with the area that has been chosen.

Q3. Among Flow, Level, Temperature and Pressure, which indicator has high level of alarms?

Answer: Pressure \& Temperature have high level of alarms. Flow and Level are not critical type of alarms.

Pressure is the most sensitive one.

Q4. In real time situation, how does operator handle the alarm that has been triggered?

Answer: There are two ways to handle the alarm.

- They can open and close valve at DCS, for those which have direct access to DCS.

- The operator will go to field where the point is not connected to DCS. The one which is connected to DCS is the one who has high priority.

\section{ACKNOWLEDMENT}

Special thanks to all staff and process engineers who had supported either directly and/or indirectly the research project.

\section{REFERENCES}

[1] Maryam K, Faisal K, and Kelly H (2009), Dynamic risk assessment using failure assessment and Bayesian theory, Journal of Loss Prevention in the Process Industries, Vol.22, Issue 5, pp.600-606.
[2] Turban E, Aronson J.E, Peng Liang T (2005), Decision Support Systems and Intelligent Systems Seventh Edition, Pearson Education Inc., New Jersey.

[3] Hollifield B R, Eddie Habibi (2007), Alarm Management: Seven Effective Methods for Optimum Performance, United States of America, Instrumentation, Systems and Automation Society (ISA).

[4] Peter Andow (2005), Alarm Management and Operator Graphic, Honeywell Process Solution for Institution of Chemical Engineers, Southampton.

[5] O. M. Foong., Suziah Sulaiman, Dayang R. A. Rambli, Alarm Prioritization System for Oil Refinery, World Congress on Engineering and Computer Science, Vol. II, pp.1012-1017. ISBN 978-988-18210-2-7.

[6] C. W. Holsapple and M. P. Sena (2005), ERP Plans and Decision-Support Benefits, Decision Support Systems, Elsevier, Vol. 38, Issue 4, pp.575-590.

[7] Anonymous (2004), Risk Assessment Matrix (RAM) Process, Michigan State University.

[8] Trochim, William M. (2006), Likert Scalling. Research Methods Knowledge Base, 2nd Edition.

[9] Zhiqiang Geng, Qunxiong Zhu, and Xiangbai Gu (2005), A fuzzy Clustering-Ranking Algorithm and Its Application for Alarm Operating Optimization in Chemical Processing American Institute of chemical Engineers, Process Safety Progress, Vol.24, No.1, pp.66-75.

[10] Oscar Castillo and Patricia Melin (2007), A New Approach for PlantMonitoring usinf Type-2 Fuzzy Logic and Fractal Theory, Studies in Fuzziness and Soft Computing, Springer Verlag, Vol. 223/2008, ISSN:1434-9922 (Print) 1860-0808 (Online.)

[11] Adam S. Markowski, M. Sam Mannan and Agata Bigoszewska (2009), Fuzzy Logic for Process Safety Analysis, Journal of Loss Prevention in the Process Industries, Vol.22, Issue 6, pp. 695-702.

[12] M. Ilangkumaran and P.Thamizhselvan (2009), Integrated Hazard and Operability Study Using Fuzzy Linguistics Approach in Petrochemical Industry, International Journal of Quality and Reliability Management, Vol.27, No.5, pp.541-557. 